\title{
La precariedad del velo corporativo para evitar el fenómeno de fraude en las sociedades ${ }^{1}$
}

The Precariousness of the Corporate Veil to Avoid the Phenomenon of Fraud in Companies

\author{
Carlos Fabián Ardila Yopasa ${ }^{2}$
}

\section{RESUMEN}

Las relaciones frente al estado y las dinámicas del mercado terminan siendo las que determinan las prácticas jurídicas. De aquí que se necesite la adopción de medidas que controlen las situaciones en las cuales priman lógicas del mercado. Se requiere una legislación que le ponga un efectivo límite al neoliberalismo salvaje que ha filtrado las lógicas de las instituciones jurídicas. En consiguiente, la figura del levantamiento del velo corporativo juega como un límite a las prerrogativas provenientes de las situaciones económicas, buscando evitar el fraude propiciado por el ocultamiento de las personas tras las sociedades de capital, las restricciones a su responsabilidad, la perpetuación jurídica y legal de su impunidad, entre otros puntos. Una figura benéfica pero insuficiente, una figura que se ha entendido como una salida en parte facilista, y por tanto se necesitan de otras medidas que la complementen para tener un real potencial de protección.

Palabras claves: velo corporativo, responsabilidad limitada, fraude

1 Fecha de recepción: 15 de diciembre de 2015. Fecha de aceptación: 21 de junio de 2016. Para citar el artículo: Ardila, C. "La precariedad del velo corporativo para evitar el fenómeno de fraude en las sociedades". Revist@ E-Mercatoria, vol. 15, № 1, enero-junio, 2016. DOI: https://doi.org/10.18601/16923960.v15n1.03

2 Estudiante de Derecho de la Universidad Nacional de Colombia. Colombiano. Contacto: cfardilay@unal.edu.co 


\section{ABSTRACT}

Relations against the state and the market dynamics end up being the determining legal practices. Hence the adoption of measures to control the situations in which market logic prevail needed. Legislation that would put a limit on cash savage neoliberalism that has leaked logic of legal institutions is required. In Therefore, the figure of piercing the corporate veil play as a restriction on the powers from the economic situations, seeking to avoid fraud led by people hiding behind corporations, restrictions on their responsibility, legal perpetuation and their legal impunity, among other things. A charity but insufficient figure, a figure that has been understood as a facile output part, and therefore need other measures that complement to have a real potential for protection.

Keywords: corporate veil, limited liability, fraud

\section{INTRODUCCIÓN}

Ningún estadio de la vida social puede primar sobre los derechos esenciales del hombre, ni siquiera los derechos patrimoniales pueden prevalecer sobre los derechos fundamentales. Ciertamente el desarrollo económico de la mano de procesos por este impulsados, como la globalización, imponen cada día un mayor control sobre los sujetos, entidades e instituciones sociales, a ello se suma la poca regulación por parte del derecho que cada vez más se defiende y populariza, en lo que se refiere a las diferentes esferas de la dimensión económica, para que se difundan prácticas en las cuales los derechos fundamentales se vean supeditados a los derechos que emanan del dominio.

En la materialidad se ve más claro debido a que factores que no deberían interferir en los estadios de la política y el derecho adquieren gran relevancia, es así como la capacidad adquisitiva, el poder de pagar una defensa técnica adecuada, y hasta figuras más nocivas aun como la manipulación de la legislación en favor de un sector, adquieren un poder tal que terminan definiendo las relaciones entre particulares en una sociedad. Las relaciones frente al estado y las dinámicas del mercado terminan siendo las que determinan las prácticas jurídicas. De aquí que se necesite la adopción de medidas que controlen cada vez más las situaciones en las cuales priman las que hemos denominado lógicas del mercado. Se requiere una legislación más "entrometida", que le ponga un efectivo limite al neoliberalismo salvaje que ha filtrado las lógicas de las instituciones jurídicas para preservar grandes baluartes, principios y fines que justifican la existencia de las mismas.

En consiguiente con lo anterior expuesto, se entiende, en este trabajo, el derecho como un sistema con una lógica inmersa y una cohesión absoluta, en el cual está la figura del levantamiento del velo corporativo. Una figura 
con todo un concepto de límite a las prerrogativas provenientes de las situaciones económicas, pues esta figura busca, evitar el fraude propiciado: por el ocultamiento de las personas tras las sociedades de capital, las restricciones a su responsabilidad, la perpetuación jurídica y legal de su impunidad, y otros puntos que analizaremos más detalladamente a lo largo de este trabajo. Por tanto es una figura benéfica, un respiro de protección a los derechos que se esconden detrás de las obligaciones incumplidas o los daños causados, que se pueden quedar sin reparar, y sin embargo, una figura que no es suficiente, una figura que se ha entendido como una salida en parte facilista al problema, lo cual le ha quitado el potencial real de protección.

Por tanto es pertinente abordar este análisis desde el contexto teórico y el origen de la figura, pasando por el tratamiento legal que tiene el levantamiento del velo corporativo en el ordenamiento jurídico de nuestro país, para finalmente proponer algunas alternativas que no pretender sustituir el levantamiento del velo corporativo, sino por el contrario lo complementarían.

\section{CAPÍTULO I \\ LEVANTAMIENTO DEL VELO CORPORATIVO}

\section{CONCEPTO Y ORIGEN}

Para estudiar la figura del velo corporativo debe tenerse un presupuesto teórico, el concepto básico de sociedad. Decimos básico debido a que el desarrollo de todo un estudio doctrinario en esta materia no es un requisito para el desarrollo del presente estudio, es suficiente con las características más fundamentales que componen el núcleo esencial de lo que se entiende por sociedad, específicamente en el contexto del ordenamiento jurídico colombiano.

La ley en esta materia es plenamente taxativa (por lo menos en el sistema colombiano), dice: "Por el contrato de sociedad dos o más personas se obligan a bacer un aporte en dinero, en trabajo o en otros bienes apreciables en dinero, con el fin de repartirse entre sí las utilidades obtenidas en la empresa o actividad social"3. Es decir que la naturaleza de la sociedad es un contrato, aunque esta difiera en ciertos puntos con el concepto clásico de contrato, por ejemplo en que un contrato es un acuerdo entre voluntades, y las sociedades por acciones simplificadas o unipersonales, pueden ser conformadas por un único miembro.

Ahora bien, existen ciertos aspectos generales de las mismas que nos llevaran a entender mejor el desarrollo de conceptos que manejaremos en el transcurso del presente trabajo. Primero, la persona jurídica, la cual se distingue de las personas que la conforman (socios) una vez que han cumplido con las formalidades impuestas en la ley para su conformación. Segundo, toda socie- 
dad se constituye con ánimo de lucro, por ende cada uno de los socios espera obtener rendimiento y este será proporcionado a la cantidad de aportes como la misma sociedad lo convenga en sus propios estatutos (siempre que esto no sea contrario a la ley). Y tercero, la entidad encargada de la vigilancia de las sociedades, la superintendencia de sociedades ${ }^{4}$.

En cuanto a la forma de participación y la responsabilidad, las sociedades se dividen en dos grandes grupos, primero sociedades de personas y segundo sociedades de capital. Esta gran clasificación subsume otra sub clasificación que está totalmente ligada a la primera, y se da en cuanto a la responsabilidad, esto es las sociedades de responsabilidad limitada y las de responsabilidad ilimitada, como el nombre de esta última clasificación sugiere simplemente se dividen en; las sociedades en las cuales los "socios" responden de manera ilimitada y los que no, esto es, los que son obligados a reparar los daños causados o las obligaciones incumplidas de acuerdo al principio que se fundamenta en el artículo 2341 del código civil "el que ba cometido un delito o culpa, que ba inferido daño a otro, es obligado a la indemnización, sin perjuicio de la pena principal que la ley imponga por la culpa o el delito cometido"s, hasta con su propio patrimonio y de manera solidaria al resto, la sociedad como si, y los socios; a) que tienen como restricción a la reparación su propio patrimonio, y b) que no responden solidariamente.

Teniendo esto en cuenta podemos pasar a explicar la diferencia general entre las sociedades de personas y las de capital, incluyendo en ellas la diversificación en la responsabilidad que acabamos de plantear, así las sociedades de personas: son sociedades en las cuales todos los socios se conocen, en estas sociedades es importante el socio como persona ya que todos participan en la dirección de la sociedad así como responden ilimitada y solidariamente, cada uno de ellos con las obligaciones de la sociedad y otra de las características de este tipo de sociedades es que la transmisibilidad de las acciones en estas está altamente restringida.

A diferencia del grupo anterior, en este otro tipo de sociedades no es importante la persona, sino su aporte en capital a la sociedad, como no existe un elemento de confianza personal en la asociación, como ya dijimos lo que se mide es la participación de los socios ${ }^{6}$, mediante la compra de acciones, que representan dicha participación, gracias a que las personas no son impor-

4 CÓRDOBA ACOSTA, PABLO ANDRÉS. Derecho de sociedades, derecho común y responsabilidad de la sociedad holding. Levantamiento del velo corporativo. Responsabilidad contractual y aquiliana. Fundación Dialnet. Revista de Derecho Privado, ISSN-e 0123-4366, Nº. $10,2006$.

5 Artículo 2341 del Código Civil.

6 CÓRDOBA ACOSTA, PABLO ANDRÉS. Derecho de sociedades, derecho común y responsabilidad de la sociedad holding. Levantamiento del velo corporativo. Responsabilidad contractual y aquiliana. Fundación Dialnet. Revista de Derecho Privado, ISSN-e 0123-4366, №. 10,2006 
tantes en este tipo de sociedades, los socios responden de acuerdo al grado de sus aportes, de hecho en la mayoría de los casos ni siquiera se conoce la identificación particular de cada socio y la transmisibilidad de las acciones es libre (en términos generales), y la representación de la sociedad puede estar en cabeza de personas ajenas a la misma sociedad.

Lo anteriormente mencionado expresa las razones que fundamentan el uso de una cierta protección a los accionarios de una sociedad $d_{i}$ limitada o anónima. Para comprender la dimensión de esta doctrina es relevante comenzar exponiendo sus orígenes. Así pues, el velo corporativo fue ilustrado por primera vez en 1897 en el caso Inglés Salomón Vs. Salomón. Con el caso se pueden extraer tres conclusiones principales. La primera, no es requisito legal y se considera irrelevante el hecho de que algunos de los accionistas no ostenten una acción. La segunda, una compañia constituida conforme a la ley de 1844 tiene personalidad jurídica separada y no per se un agente. Y la tercera, el uso de obligaciones en lugar de acciones servirá como instrumento para proteger a los inversores.

Así pues, la personería jurídica existe solo con que tenga legitimidad de su acto fundacional y sea inscrita legalmente ${ }^{7}$, no obstante puede propiciar situaciones de abuso o fraude. Así como dice el viejo refrán "hecha la ley, hecha la trampa". Bajo estas circunstancias los jueces empezaron formular medidas que midieran las pautas de las sociedades de responsabilidad limitada. Seguidamente fue en los Estado Unidos, donde el velo corporativo se desarrolló aún más por los tribunales. La jurisprudencia norteamericana definió el velo como medio para evitar el abuso que se puede hacer de la personalidad jurídica, no anulando la sociedad, sino que, en casos concretos de abusos, se dicten sentencias justas ${ }^{8}$.

En consecuencia, el velo corporativo se interpreta, gracias a su origen histórico, como una protección que actúa como limitación a la responsabilidad en la medida en que protege que un accionista o propietario no incurra en la deuda que la empresa adquiere 9 . En otras palabras, cuando la persona jurídica se encuentra ante una demanda o se ha cometido acciones ilícitas a través de esta, esta limitación se demuestra, por lo menos en presunción, en que los socios, por un lado separan sus activos patrimoniales de los de la sociedad y por lo tanto, en caso del pago de obligaciones, solo se pagara con el patrimonio de la empresa. Y de otro lado como complemento general a la nombrada pro-

7 FERNÁNDEZ SESSAREGO, CARLOS. "Persona, Personalidad, Capacidad, Sujeto de Derecho: Un reiterado y necesario deslinde conceptual en el umbral del siglo XXI". En Doctrina Contemporánea. Normas Legales, Trujillo, 2003, pp. 3-26.

8 FIGUEROA, DANTE. Levantamiento Del Velo Corporativo Latinoamericano: Aspectos Comparados Con El Derecho Estadounidense (Piercing the Corporate Veil in Latin América: Comparative Aspects with U.S. Law). November 30, 2011. Ibíd. 
tección, se eximen de la responsabilidad sobreviniente por actuaciones ilícitas en las que se vea involucrada la sociedad y demandas que recaigan sobre ella ${ }^{10}$.

Ahora bien el termino corporativo del velo es un tema que aun hoy no está definido en su totalidad, pero para lógicas de este trabajo se expresa su utilización en base a que una vez que una empresa se hace corporación, se convierte en su propia persona jurídica, por lo tanto es una persona jurídi$\mathrm{ca}$, distinta y separada de las personas que la forman, son dueñas o invierten en ella ${ }^{11}$. Entonces conserva sus derechos y responsabilidades como si fuera un dueño o se encarga de la realización de contratos, y puede demandar o ser demandada únicamente en nombre propio. Es por ello que el velo al ser una herramienta en función de proteger esta premisa se menciona como velo corporativo.

En la actualidad, el velo corporativo se ha convertido en un instrumento útil para la realización de fraudes y acciones ilícitas. El profesor Serick de la Universidad de Heidelberg ${ }^{12}$, dice que existen supuestos para que se realice el abuso de la personalidad jurídica, como lo son: el fraude a la ley, el fraude o violación al contrato, y el daño fraudulento ocasionado a terceros. Con estos, el profesor da a entender que lo que ha sido violado es el deber de buena $\mathrm{fe}^{13}$ que lleva cualquier ordenamiento jurídico, es decir, que con el abuso de la personalidad jurídica se puede ocasionar sátira contra las disposiciones legales que se vinculen al caso.

En opinión de otro profesor, el profesor Dobson ${ }^{14}$, este dice que las condiciones para que se de abuso del derecho se resumen en situaciones como: cuando el ánimo de causar un perjuicio aparece como exclusivo fin del acto, cuando fueron contrariados los fines propuestos por las leyes para establecer la protección a determinados actos, cuando el ejercicio de un derecho haya excedido los límites que impone la buena fe, la moral y las buenas costumbres.

Como se puede ver, respecto a las dos perspectivas los criterios para establecer si existe o no el abuso de un derecho, en este caso de personería jurídica

10 BOLDO RODA, CARMEN. Levantamiento del velo y persona jurídica en el derecho privado español, Edit. Arazandi, Pamplona, España, 1996, p. 143.

11 QUIROGA PERICHE, CARLOS ENRIQUE. "El Uso abusivo de la Responsabilidad Limitada. Protección de los acreedores de una Sociedad Anónima frente al uso abusivo de la Responsabilidad Limitada de los socios, sin afectar la subjetividad jurídica de la sociedad". Tesis para optar por el título de Abogado. Universidad Nacional de Trujillo, Facultad de Derecho, Trujillo, 2004, 187 pp.

12 Serick, Rolf. "Apariencia y realidad de las sociedades mercantiles. El abuso del derecho por medio de la persona jurídica". Traducción por José Puig Brutao, Barcelona, 1958.

13 Art. 83 de la C.P. "las actuaciones de los particulares y de las autoridades públicas deberán ceñirse a los postulados de la buena fe, la cual se presumirá en todas las gestiones que aquellos adelanten ente estas".

14 Dobson, Juan M. "El abuso de la personalidad jurídica". Depalma, Buenos Aires, 1985. p. 31. 
y su responsabilidad limitada, son muy distintos dependiendo de su enfoque de interpretación ${ }^{15}$. Sin embargo, se puede concluir que el abuso se puede determinar en la medida que la finalidad de la responsabilidad se desvía de lo establecido por la norma regulatoria ${ }^{16}$. Para ejemplificar esta premisa, ante la norma la finalidad de las sociedades está guiada a obtener logros comunes para los socios cuando se pretende con la creación de la sociedad beneficiar a algunos socios y no a todos se desvía del propósito teológico que la norma dispone a la sociedad.

En consecuencia, los abusos cometidos por medio de la personería jurídica y la responsabilidad limitada han producido indignación, y el esfuerzo de la jurisprudencia, de la doctrina y de la legislación para combatir estos abusos ${ }^{17}$. Como mecanismo para tal fin se ha mantenido desde décadas la utilización de "levantar o corregir el velo".

\section{CAPÍTULO II \\ LEVANTAMIENTO DEL VELO CORPORATIVO EN COLOMBIA}

Los primeros países que desarrollaron teorías para resolver los abusos que se cometían bajo la figura de la personería jurídica fueron los países que estaban bajo el particular sistema de common law ${ }^{18}$, en ellos se inicia la doctrina conocida en un principio como "disregar of legal entity" (desentenderse de la entidad legal) que finalmente adquirió el nombre de "lifting of piercing the corporate veil" (levantar o correr el velo), En otros países la configuración de esta doctrina no ha sido tan fácil ${ }^{19}$.

En Colombia, en primera instancia, se han llevado a cabo discusiones respecto a si es posible aplicar la teoría del abuso de la personería jurídica en la medida que existen dos puntos de vista, primero, que la aplicación de esta teoría no es posible porque existe un vacío, y segundo, que la aplicación de

15 DE ANGEL YAGÜEZ, RICARDO. La doctrina del "Levantamiento del Velo" de la Persona Jurídica en la Jurisprudencia. Cuarta Edición, Civitas, Madrid, 1997, pp. 62-63.

16 BORDA, GUILLERMO JULIO. El abuso de la persona jurídica en el contrato de sociedad, en Contratación Contemporánea 2, Ed. Temis-Palestra 2001, p. 265.

17 AMBROSIO LEONELLI, PAOLO / URRA ESCOBAR, RODRIGO ANDRÉS y NOVOA MUÑOZ, GABRIELA YOLANDA. Abuso de la personalidad jurídica, escuela de derecho, Universidad Católica De Temuco, TEMUCO, Octubre 29 de 2004.

18 Los países que adoptan el derecho anglosajón son por lo general aquellos que formaron parte de las colonias y protectorados ingleses, incluyendo a los Estados Unidos. Este sistema se caracteriza por: No siempre existe una constitución escrita o leyes codificadas; Las decisiones judiciales son forzosas - las decisiones del tribunal de última instancia pueden ser anuladas por el mismo tribunal o a través de legislación; Amplia libertad de contratación; y Generalmente, todo está permitido si no está prohibido por ley.

19 HAMILTON. ROBERT W. The Law of Corporations in a Nutshell. West Publishing Co. St. Paul, Minn, 1991, p. 81. 
esta teoría se permite en la medida que este fundamentada en el abuso del derecho. Respecto al primero, se argumenta que no existe tal vacío ya que la teoría se fundamenta en el abuso del derecho, esto nos da razón para optar por el segundo punto de vista que plantea exactamente esto. De igual forma podemos confirmar que el abuso de personería jurídica consagrada como abuso de derecho se aplica en Colombia gracias a normas establecidas como lo es el artículo 830 del código de comercio ${ }^{20}$, el cual expresa: " el que abuse de sus derechos estará obligado a indemnizar los perjuicios que cause". Así pues, la teoría del abuso de la personalidad jurídica y su consecuencia inmediata que es el desmantelamiento del velo corporativo, no son otra cosa que una aplicación del abuso del derecho, concretado en la utilización indebida de la personalidad jurídica ${ }^{21}$. En este orden de ideas, el abuso de derecho consagrado en el artículo 830 del C. de Comercio es suficiente para soportar la teoría del abuso de la personalidad jurídica en el derecho societario colombiano.

De igual forma en el derecho societario la limitación de la responsabilidad se constituye como un principio fundamental, ya que facilita el desarrollo económico a través de las sociedades anónimas y de responsabilidad limitada impidiendo la comunicación de las deudas sociales con el patrimonio personal de los socios. Este principio normativo ha presentado excepciones en los últimos años no tanto por las normas que posibilitan de levantamiento del velo, sino en virtud de la jurisprudencia que resulta incoherente y contradictoria.

Respecto a los socios de sociedades colectivas y en comandita se elimina el privilegio de la limitación de la responsabilidad, de tal manera que esos socios responderán con su propio patrimonio frente a las obligaciones sociales. Cuando los socios deciden crear una sociedad colectiva o en comandita entienden que por disposición de la ley, no podrán ser protegidos por el velo corporativo ${ }^{22}$.

En las sociedades de responsabilidad limitada y anónima, la ley ha estructurado un velo que protege a los socios frente a las obligaciones de la sociedad, quien es una persona jurídica diferente de ellos. En la medida que existen distintas disposiciones para cada tipo de sociedad el legislador ha considerado necesario hacer excepciones a la regla de la limitación de responsabilidad, con el fin de evitar el fraude a la ley. Sin embargo, debe tenerse en cuenta que, es según el origen de las obligaciones de una sociedadi de la aplicación de normas de carácter tributario ${ }^{23}$ o se contraen a favor de la administración

20 Art. 830 del Código de Comercio.

21 ROSEMBUJ, TULIO. El fraude de ley, la simulación y el abuso de las formas en el derecho Tributario. Monografías jurídicas (2, ${ }^{a}$ ed.), Editorial Marcial Pons, Madrid 1999. 
pública ${ }^{24}$, que el legislador, sin tener en cuenta si los socios han actuado de buena o mala fe, ha planteado el levantamiento del velo.

La Ley 190 de 1995, llamada el estatuto anticorrupción, estableció otra hipótesis de levantamiento del velo corporativo, la cual expresa que el levantamiento del velo se hace para evitar la gestión de acciones ilícitas bajo la figura de la persona jurídica. Este Estatuto deja que las autoridades judiciales omitan la limitación de la personificación jurídica y vallan tras los responsables de la conducta punible y beneficiarios reales ${ }^{25} \mathrm{y}$ procedan a sancionarlos.

El Código de Comercio también consagra supuestos de levantamiento al desestimar absolutamente la personalidad de la sociedad a través de una declaratoria de nulidad por causa u objeto ilícito ${ }^{26}$.

El artículo 37 de la Ley 142 de 1994, consagra otro supuesto al exponer que:

"Para los efectos de analizar la legalidad de los actos y contratos de las empresas de servicios públicos, de las comisiones de regulación, de la Superintendencia y de las demás personas a las que esta ley crea incompatibilidades o inhabilidades, debe tenerse en cuenta quienes son, sustancialmente, los beneficiarios reales de ellos, y no solamente las personas que formalmente los dictan o celebran. Por consiguiente, las autoridades administrativas y judiciales harán prevalecer el resultado jurídico que se obtenga al considerar el beneficiario real, sin perjuicio del derecho de las personas de probar que actúan en procura de intereses propios, y no para hacer fraude a la ley".

Por otra parte, en el derecho penal, la teoría del levantamiento del velo corporativo ha sido institucionalizada en el artículo 82 del Código de Procedimiento Penal, el cual dispone:

"Suspensión y cancelación de la personería jurídica. En cualquier momento y antes de presentarse la acusación, a petición de la Fiscalía, el juez de control de garantías

24 El parágrafo $3 .^{\circ}$ del Artículo 7. ${ }^{\circ}$ de la Ley 80 de 1993 dispone: "En los casos en que se conformen sociedades bajo cualquiera de las modalidades previstas en la ley con el único objeto de presentar una propuesta, la responsabilidad y sus efectos se regirá por las disposiciones previstas en esta ley para los consorcios".

25 Artículo 1.2.1.3 de la Resolución 400 de 1995 proferida por la Superintendencia de Valores. La noción de beneficiario real se encuentra ligada a la capacidad decisoria que pueda tener o llegar a tener una persona o grupo de personas respecto de una acción de una sociedad. Esto es, ostentar la facultad de votar en la elección de directivas o representantes o, de dirigir y controlar dicho voto, así como la facultad de enajenar y ordenar la enajenación, ya sea directa o indirectamente, en virtud de un contrato, convenio o de cualquier otra manera.

26 El artículo 104 del Código de Comercio dispone: "Habrá objeto ilícito cuando las prestaciones a que se obliguen los asociados o la empresa, o la actividad social, sean contrarias a la ley o al orden público. Habrá causa ilícita cuando los móviles que induzcan a la celebración del contrato contraríen la ley o el orden público y sean comunes o conocidos por todos los socios". 
ordenará a la autoridad competente que, previo el cumplimiento de los requisitos legales establecidos para ello, proceda a la suspensión de la personería jurídica o al cierre temporal de los locales o establecimientos abiertos al público, de personas jurídicas o naturales, cuando existan motivos fundados que permitan inferir que se han dedicado total o parcialmente al desarrollo de actividades delictivas. Las anteriores medidas se dispondrán con carácter definitivo en la sentencia condenatoria cuando exista convencimiento más allá de toda duda razonable sobre las circunstancias que las originaron".

En relación con este asunto, la Corte Suprema de Justicia expreso que la figura de personería jurídica para efectos comerciales y civiles es un ente diferente a los socios, en una afirmación que no se debe extender a cuestiones de derecho penal. En la situación en que el patrimonio de una persona jurídica sirva para cometer acciones delictivas no quiere decir que la empresa sea la responsable ${ }^{27}$.

En consecuencia de las presuntas hipótesis de levantamiento de velo que se han mencionado, se puede determinar que existen elementos trasversales que lo definen, en primer lugar, se rompe el velo cuando hay fraude o acto ilícito. En segundo lugar, se levanta a través de una convención. Y en tercer lugar, se corrige a través de previsiones normativas en las que se busca proteger a unos acreedores.

Recopilando, se entiende que el levantamiento del velo corporativo no es otra cosa que el desconocimiento de la limitación de la responsabilidad al hacer responsables directos a los asociados ${ }^{28}$. Ejemplo de ello es el caso de la personificación jurídica en la sociedad anónima y de responsabilidad limitada como se desconoce la limitación de responsabilidad ${ }_{i}$ la responsabilidad de los asociados llegaba hasta el valor de sus aportes, y se los hace responsables ilimitadamente. Así pues, cuando se presentan dichas situaciones la utilidad de las herramientas legales de la figura aquí mencionada se justicia en la médica en que la actuación maliciosa coloca en descubierto que no se conoce realmente el límite de la responsabilidad de los socios o accionantes.

Los beneficios adquiridos por el levantamiento de velo están principalmente dirigidos a los miembros de las sociedades ${ }^{29}$, esta afirmación se justifica con la finalidad de esa figura, la cual consiste en acabar la corrupción interna en las sociedades, a través de mecanismos que ayuden a implementar herramientas legales para combatir como por ejemplo llevar a cabo investigaciones de los delitos administrativos. 
Sin embargo el levantamiento del velo no ha podido resolver todas las eventualidades que el legislador pretendía con dicha formulación, esto se demuestra con el análisis de la corte constitucional, en cual se expone como la corte ha tenido que realizar el pago de obligaciones laborales en las corporaciones que se ven protegidas por el velo corporativo.

\section{CONCLUSIONES PRELIMINARES}

Las dimensiones de alcance del velo corporativo, son tan extensas que un estudio de todas las eventualidades fácticas para las que se puede prestar, teniendo en cuenta claro está que estas sean o se puedan considerar como negativas, y en sentido más específico que estas se puedan prestar para el fraude, se dificulta altamente, se hace un camino espinoso debido a la mencionada extensión. En consiguiente, el velo corporativo es un instrumento expedito a la hora de realizar fraude. Aunque hay que hacer la salvedad, que esto va en demerito de los principios, fundamentos y fines con los cuales fue creado. Con ello se puede concluir que la protección que el levantamiento del velo corporativo presta, la restricción a la responsabilidad emanada de la misma, inclusive el ocultamiento de la identidad ante el ojo público, son prerrogativas que permiten y hasta podríamos decir propician la realización del fraude.

Ello en tanto que, el levantamiento del velo corporativo, es una medida adecuada y bien racionalizada, de protección y limitación a la figura del velo, en su trasfondo y fundamento teórico, pero su desarrollo en la práctica, el cómo se ha entendido y manejado en el ordenamiento jurídico colombiano, deja mucho que desear, esto se demuestra en que varias ocasiones la corte constitucional ha tenido que venir a aclarar, y por así decirlo redefinir el concepto, por lo cual podemos concluir que el levantamiento del velo corporativo entendido y manejado como se ha hecho hasta ahora en el sistema jurídico colombiano, no es la medida más idónea, o por lo menos le queda todavía camino que transcurrir, en el proceso para lograrlo.

Si bien la teoría del levantamiento del velo corporativo ha sido, en el derecho comparado, aceptada, es indudable que en nuestro medio jurídico no ha sido planteada como una solución general y definitiva frente a grupos empresariales donde alguna de sus filiales se encuentre en incapacidad de cumplir sus obligaciones frente a terceros. Es por ello que en la práctica jurídica se han intentado otras alternativas que ofrece el Derecho para lograr el pago frente a deudores relacionados, como lo son: la acción pauliana, la acción ordinaria de responsabilidad extracontractual o la acción de inoponibilidad.

La principal razón para que se de esta situación es que la interpretación de artículos, como el artículos 19 de la Ley $N^{\circ} 18.046^{30}$, sobre Sociedades Anó- 
nimas, el artículo 2 de la Ley $N^{\circ} 3.918^{31}$, sobre Sociedades de Responsabilidad Limitada y el artículo 2053 inciso segundo del Código Civil, entre otros, ha consagrado un principio de separación entre la entidad legal y sus accionistas o socios, con lo cual la teoría del levantamiento del velo corporativo queda totalmente restringida y excepcional.

Como ejemplo de una de esas alternativas; la acción de inoponibilidad, la sentencia de la corte suprema de 2 de junio de 2009 (rol n 1527-2008) constituye un interesante caso de análisis y es un avance en la medida en que, en primer lugar, se pronuncia explícitamente sobre el levantamiento del velo, aceptándolo como válido y, por ende, abriendo la posibilidad para que se presenten nuevas discusiones en torno a la materia que permitan ir dilucidando el alcance de la doctrina. Y en segundo lugar, es clarificadora respecto al concepto de levantamiento del velo, como respecto de la explicación de su necesidad práctica, los supuestos para que opere y los principios que resguarda.

Otro caso en donde la corte se ha pronunciado para optar medidas de reforzamiento del levantamiento de velo tiene que ver con la situación que se da respecto al pago de obligaciones laborales ${ }^{32}$. Dicha pronunciación es resultado de las tutelas que la corte ha realizado en materia de derechos fundamentales provenientes del trabajo que se ven vulnerados cuando se utiliza el levantamiento del velo. La corte puede reforzar esta figura con su pronunciamiento en la medida que busca sentar una jurisprudencia de cómo se puede entender esta medida, reinterpretar y llevar a horizontes que se han dejado de lado, materias de igual transcendencia como los derechos laborales.

Retomando los párrafos y menciones anteriores, se entiende entonces, que en relación con el lugar que ha ocupado la corte constitucional, y aun a pesar de las dimensiones exorbitantes sobre las que puede recaer el abuso del velo corporativo, se pueden encontrar maneras de preservar los derechos fundamentales, y defender los principios últimos del sistema jurídico, y esta defensa puede y debe estar en cabeza de la corte constitucional como guarda de la

obligados a devolver a la caja social las cantidades que hubieren percibido a título de beneficio. En caso de transferencia de acciones suscritas y no pagadas, el cedente responderá solidariamente con el cesionario del pago de su valor, debiendo constar en el título las condiciones de pago de la acción.

31 Art. $2^{\circ}$. Las sociedades con responsabilidad limitada, sean civiles o comerciales, se cons tituirán por escritura pública que contendrá, además de las enunciaciones que expresa el artículo 352 del Código de Comercio, la declaración de que la responsabilidad personal de los socios queda limitada a sus aportes o a la suma que a más de esto se indique.

32 El Código Sustantivo del Trabajo señala en el artículo 36: "''Son solidariamente responsables de todas las obligaciones que emanen del contrato de trabajo las sociedades de personas y sus miembros y éstos entre sí en relación con el objeto social y sólo hasta el límite de responsabilidad de cada socio, y los condueños o comuneros de la misma empresa entre sí, mientras permanezcan en la indivisión". 
constitución y máximo órgano de administración de justicia en los términos de los principios constitucionales.

Para finalizar, respondiendo de manera más específica al cuestionamiento con el que iniciamos el presente trabajo, el levantamiento del velo corporativo no es una medida suficiente para realizar un efectivo contrapeso, a la posibilidad del abuso del velo corporativo, que se requieren por ende medidas que sirvan para dinamizar, apoyar y subsanar las falencias del levantamiento, que un ejemplo de esto es la manera en la que la corte constitucional, ha abordado el problema auscultando ciertos puntos en los que el simple levantamiento, no da para administrar de manera correcta el derecho (en sentido laxo), y estas medidas son realmente necesarias para poder proteger los bienes más apreciados ante simples derechos que protegen el mero patrimonio y no al ser humano.

\section{BIBLIOGRAFÍA}

AMBROSIO LEONELLI, PAOLO / URRA ESCOBAR, RODRIGO ANDRÉS y NOVOA MUÑOZ, GABRIELA YOLANDA. Abuso de la personalidad jurídica, escuela de derecho, Universidad Católica de Temuco, Temuco, Octubre 29 de 2004.

ANÓNIMO. "línea jurisprudencial del levantamiento del velo". Líneas jurisprudenciales. Grupo de investigación en derecho privado. Universidad Sergio Arboleda.

BOLDO RODA, CARMEN. Levantamiento del velo y persona jurídica en el derecho privado español, Edit. Arazandi, Pamplona, España, 1996.

BORDA, GUILLERMO JULIO. El abuso de la persona jurídica en el contrato de sociedad, en Contratación Contemporánea 2, Ed. Temis-Palestra, 2001.

CÓRDOBA ACOSTA, PABLO ANDRÉS. Derecho de sociedades, derecho común y responsabilidad de la sociedad holding. Levantamiento del velo corporativo. Responsabilidad contractual y aquiliana. Fundación Dialnet. Revista de Derecho Privado, ISSN-e 0123-4366, n. ${ }^{\circ}$ 10, 2006.

DE ANGEL YAGÜEZ, RICARDO. La doctrina del "Levantamiento del Velo" de la Persona Jurídica en la Jurisprudencia. Cuarta Edición, Civitas, Madrid, 1997.

DÍAZ CAPMANY, FELIPE. "La doctrina del levantamiento del velo de la persona jurídica en el proceso de creación del derecho"-1ª ed. Publicación: Barcelona: Rosaljai, 1996, Descripción física: 261 p.

FERNÁNDEZ SESSAREGO, CARLOS. "Persona, Personalidad, Capacidad, Sujeto de Derecho: Un reiterado y necesario deslinde conceptual en el umbral del siglo XXI". En Doctrina Contemporánea. Normas Legales, Trujillo, 2003. 
FIGUEROA, DANTE. Levantamiento del Velo Corporativo Latinoamericano: Aspectos Comparados con el Derecho Estadounidense (Piercing the Corporate Veil in Latin América: Comparative Aspects with U.S. Law). November 30, 2011. Available at SSRN: http://ssrn.com/abstract=1966790 or http://dx.doi. org/10.2139/ssrn.1966790

HAMILTON. ROBERT W. The Law of Corporations in a Nutshell. West Publishing Co. St. Paul, Minn, 1991.

HEIDELBERG, ROLF SERIF. "Apariencia y realidad de las sociedades mercantiles. El abuso del derecho por medio de la persona jurídica", Barcelona, 1958.

HURTADO COBLES, JOSE. La doctrina del levantamiento del velo societario (2000), Supuestos de aplicación de la doctrina del levantamiento del velo Editorial Atelier, Barcelona, 2000.

JARAMILLO HERRERA, LIYER ANDREA. Desestimación de la personalidad jurídica en el derecho societario Colombiano. Revista CES Derecho. Universidad CES Facultad de Derecho. Vol. 2, n. ${ }^{\circ} 2$ (2011), 24 de noviembre de 2011.

LEÓN BARANDIARÁN, JOSÉ. Exposición de Motivos y Comentarios al Título Preliminar, en Delia Revoredo de Debakey (compiladora), Comisión encargada del Estudio y Revisión del Código Civil: Código Civil. Vol. IV. Lima, 1985.

LEÓN ROBAYO, EDGAR IVÁN / RINCÓN CÁRDENAS, ERIK y LÓPEZ CAS TRO, YIRA. Levantamiento del velo corporativo, panorama y perspectivas. El caso colombiano. Universidad Mayor de Nuestra Señora del Rosario, facultad de jurisprudencia. Bogotá. Colección textos de jurisprudencia. Editorial Universidad del Rosario, 2010.

MORALES QUINTANILLA, RAMÓN ANTONIO. "El levantamiento del velo de la personalidad jurídica societaria (desde la perspectiva jurídica salvadoreña)". Tesis doctoral para optar al grado de Doctor En derecho pluralista público y privado. Universidad Autónoma de Barcelona-Agencia Española de Cooperación Internacional. El Salvador, enero de 2006.

QUIROGA PERICHE, CARLOS ENRIQUE. "El Uso abusivo de la Responsabilidad Limitada. Protección de los acreedores de una Sociedad Anónima frente al uso abusivo de la Responsabilidad Limitada de los socios, sin afectar la subjetividad jurídica de la sociedad". Tesis para optar por el título de Abogado. Universidad Nacional de Trujillo, Facultad de Derecho, Trujillo, 2004.

REYES VILLAMIZAR, FRANCISCO. Derecho Societario I, Ed. Temis, 2002.

ROSEMBUJ, TULIO. El fraude de ley, la simulación y el abuso de las formas en el derecho Tributario. Monografías jurídicas (2. ${ }^{a}$ ed.), Editorial Marcial Pons, Madrid, 1999. 
SÁNCHEZ MORALES, GUSTAVO CESAR. Rasgando las vestiduras de la dama sociedad: la teoría del levantamiento del velo societario, presupuestos necesarios para su aplicación práctica. Universidad de San Martín de Porres, facultad de derecho, BOLETIN CORPORATE AND LEGAL, Centro de Estudios de Derecho Corporativo. Investigaciones de alumnos.

UGARTE VIA, JORGE. Fundamentos y acciones para la aplicación del levantamiento del velo en Chile. Revista Chilena de Derecho, vol. 39 n. ${ }^{\circ}$ 3, 2012.

URBINA MOLFINO, IGNACIO. Levantamiento del velo corporativo. Sentencia de la corte suprema de 2 de junio de 2009 ( $\left.r o l n .{ }^{\circ} 1527-2008\right)$. Piercing the corporate veil. Revista Chilena de Derecho, vol. 38 n. ${ }^{\circ}$ 1, 2011. 